02

\title{
Усиление флуоресценции и комбинационного рассеяния молекул цианинового красителя на поверхности наночастиц серебра, покрытых кремнием
}

\author{
(C) А.Н. Камалиева, Н.А. Торопов, К.В. Богданов, Т.А. Вартанян
}

Университет ИТМО,

197101 Санкт-Петербург, Россия

e-mail: aisylu.kamaliewa@yandex.ru

Поступила в редакцию 24.10.2017 г.

\begin{abstract}
Разработана методика создания композитной структуры на основе серебряных наночастиц и тонкой защитной кремниевой пленки $(\mathrm{Ag} N P s / \mathrm{Si})$. Наблюдалось усиление флуоресценции и комбинационного рассеяния молекул цианинового красителя, нанесенных поверх созданной наностуктуры. Исследованы оптические свойства и стабильность морфологии частиц при контакте с растворами цианинового красителя в органических растворителях. Показано, что композитная $\mathrm{AgNPs} / \mathrm{Si}$ структура может быть многократно использована в качестве ГКР-активной поверхности.
\end{abstract}

DOI: $10.21883 / \mathrm{OS} .2018 .03 .45652 .248-17$

\section{Введение}

Давно известно, что вблизи наночастиц благородных металлов оптические свойства органических молекул могут сильно изменяться. Это связано с явлением плазмонного резонанса, сопровождающимся усилением поля вблизи частицы по сравнению с полем падающей волны. При помещении органических молекул в ближнее поле плазмонных наночастиц можно наблюдать увеличение поглощения, усиление или тушение флуоресценции, а также явление гигантского комбинационного рассеяния света (ГКР) [1-9].

На сегодняшний день спектроскопия комбинационного рассеяния является широко используемым методом для определения компонентного состава и структуры вещества, а также при исследовании межмолекулярных взаимодействий. Этот широкий спектр возможностей важен для применений в биологии, медицине, экологии и фармацевтике. Кроме того, ГКР позволяет исследовать свойства молекул при очень низких концентрациях, вплоть до детектирования спектров одиночных молекул [10].

В основе данного метода лежит использование ГКРактивных поверхностей, на которые наносится исследуемое вещество. Для создания ГКР-активных поверхностей чаще всего используют золото, серебро и платину, реже медь и алюминий [11]. Тем не менее серебряные и даже золотые наночастицы могут меняться при контакте с исследуемыми молекулами и растворителями, что, с одной стороны, негативно влияет на их морфологию, плазмонные свойства и затрудняет интерпретацию получаемых спектров. С другой стороны, нежелательная модификация серебряных и золотых ГКР-поверхностей с высокой чувствительностью делает их использование практически одноразовым, что удорожает методы, использующие комбинационное рассеяния света [12].
В ряде работ описаны новые методы создания ГКР-активных поверхностей на основе гибридных наноструктур [13,14]. Но одновременное выполнение ряда требований для ГКР-активных поверхностей попрежнему остается трудной задачей. Среди них эффективное увеличение сигнала, воспроизводимость результатов и приемлемая стоимость. Поэтому разработка новых вариантов ГКР-активных поверхностей остается актуальной.

В настоящей работе для создания ГКР-активных композитов были использованы серебряные наночастицы. Наш выбор обусловлен тем, что наночастицы серебра по сравнению с другими плазмонными материалами обладают самой большой величиной усиления в оптическом диапазоне, кроме того, серебро является сравнительно недорогим материалом. Структура из наночастиц серебра была покрыта тонким слоем кремния. Кремний является более устойчивым к растворителям материалом, что является привлекательным с прикладной точки зрения свойством, так как позволяет использовать композит многократно. Для того чтобы сохранить плазмонные эффекты на поверхности, эквивалентная толщина слоя кремния подбиралась соизмеримой с размером серебряных наночастиц.

Для выяснения возможности использования композитной структуры $\operatorname{AgNPs} / \mathrm{Si}$ в качестве ГКР-активной поверхности она была исследована при покрытии тонким слоем цианинового красителя.

\section{Экспериментальная часть}

Островковые пленки, состоящие из наночастиц серебpa, были получены методом осаждения паров металла на кварцевые подложки в вакуумной камере PVD 75 Kurt J. Lesker при давлении остаточных газов порядка $10^{-7}$ Torr. Рост наночастиц серебра происходил по 

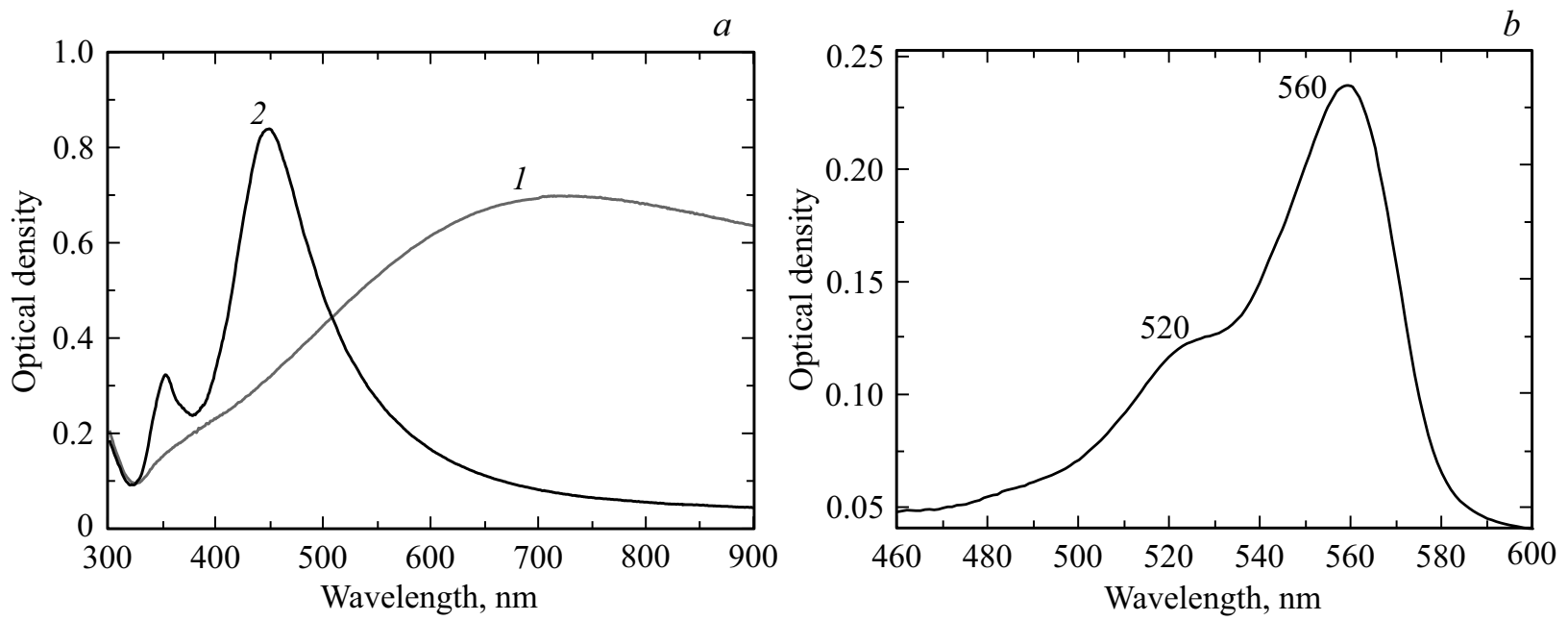

Рис. 1. (a) Спектр оптической плотности островковой серебряной пленки с эквивалентной толщиной $10 \mathrm{~nm}$ до отжига $(1)$ и после термического отжига $(2) ;(b)$ спектр оптической плотности слабо концентрированного этанольного раствора цианинового красителя.
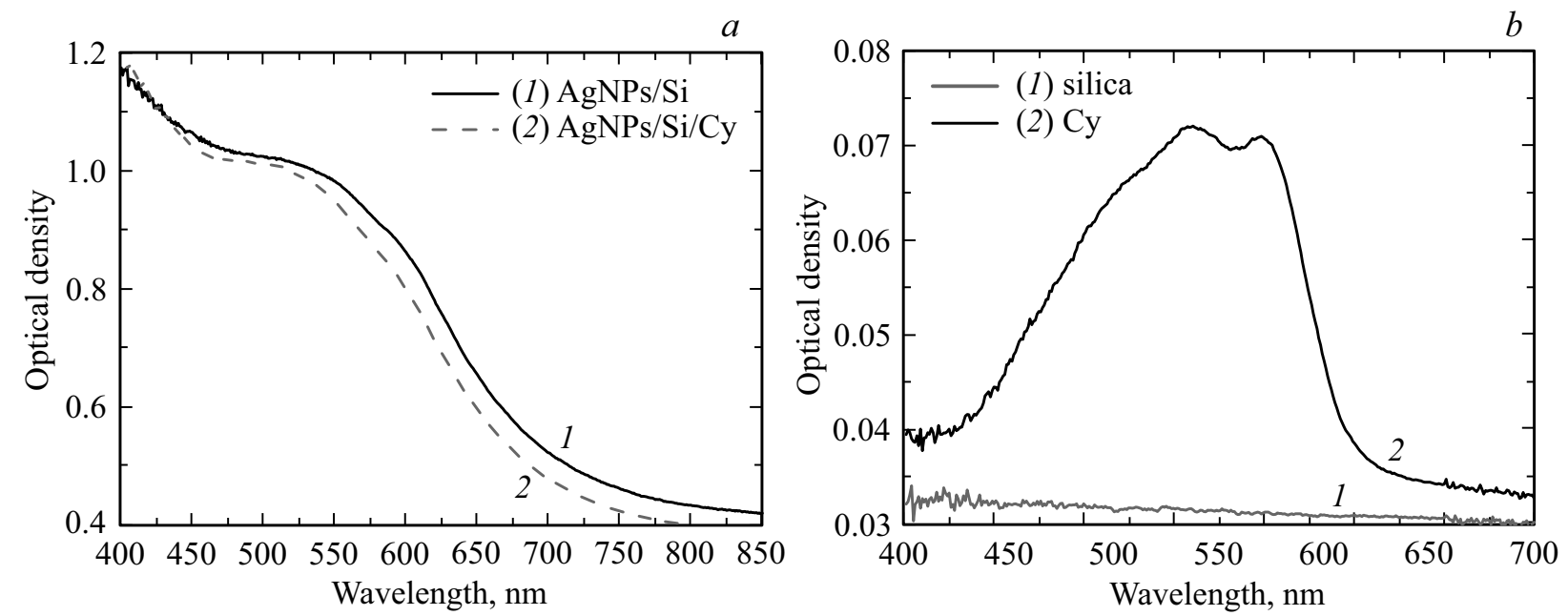

Рис. 2. Спектры оптической плотности $(a)$ наночастиц серебра, покрытых кремнием (1), и наночастиц серебра, покрытых кремнием и тонкой пленкой цианинового красителя (2), (b) кварцевой подложки (1) и тонкой пленки цианинового красителя на кварцевой подложке (2).

механизму Вольмера-Вебера на дефектах поверхности. Эквивалентная толщина островковой серебряной пленки определялась с помощью кварцевого измерителя толщины и составляла $10 \mathrm{~nm}$. После напыления серебра образец отжигался при $200^{\circ} \mathrm{C}$. На рис. $1, a$ представлены спектры оптической плотности островковых пленок. Кривая 1 - спектр образца, измеренный сразу после напыления, кривая 2 - после термического отжига. Сoгласно данным, полученным с помощью сканирующего электронного микроскопа, до отжига поверхность наночастиц представляет собой пленку, близкую к сплошной, с множеством сплюснутых наноостровков нерегулярной формы, расположенных на малых расстояниях друг от друга. При нагревании форма наноостровков за счет поверхностной диффузии атомов серебра [15] приближается к сферической, а расстояние между ними увеличивается, что приводит к коротковолновому сдвигу и сужению спектра экстинкции. Средний радиус наночастиц в отожженной пленке составляет $65 \mathrm{~nm}$.

Известно, что островковые серебряные пленки недостаточно устойчивы к действию растворителей [16], кроме того, поверхность такой пленки можно легко повредить механически. Поэтому для создания устойчивой композитной структуры на поверхность отожженной островковой серебряной пленки в той же вакуумной камере напылялся слой кремния толщиной $65 \mathrm{~nm}$.

Для приготовления тонких органических слоев был использован этанольной раствор цианинового красителя $(C y)$ 3, 3'-диэтилтиакарбоцианин иодид. Пример спектра поглощения раствора цианинового красите- 
ля представлен на рис. $1, b$. Для создания тонкого слоя красителя раствор с концентрацией красителя $1.25 \mathrm{mmol} / 1$ объемом $50 \mu \mathrm{l} \mathrm{c} \mathrm{помощью} \mathrm{механического}$ дозатора наносился на поверхность $\mathrm{AgNPs} / \mathrm{Si}$ композита методом центрифугирования (spin-coating) при скорости вращения $3000 \mathrm{~min}^{-1}$. Для сравнения раствор цианинового красителя в том же количестве и при тех же условиях наносился на чистую кварцевую подложку. Количество красителя на подложках сравнивалось путем растворения тонкой пленки и измерением концентраций получаемых растворов. Разница в спектрах составляла менее $10 \%$. На рис. 2 представлены спектры оптической плотности полученных образцов. Небольшое уменьшение оптической плотности композита при нанесении красителя, по-видимому, связано с просветляющим действием красителя по отношению к кремнию, имеющему более высокий показатель преломления.

Спектры поглощения и флуоресценции исследуемых образцов были получены с помощью спектрофотометpa СФ-56 (ЛОМО) и спектрофлуориметра RF-5301PC (Shimadzu) соответственно. Спектры комбинационного рассеяния были получены на конфокальном микроспектрометре комбинационного рассеяния света inVia (Renishaw).

\section{Результаты и обсуждение}

На рис. 3 представлены нормированные спектры флуоресценции тонкой цианиновой пленки на поверхности чистой кварцевой подложки (1) и тонкой цианиновой пленки на поверхности подложки со структурой $\mathrm{AgNPs} / \mathrm{Si}$ (2). Толщина пленки в обоих образцах одинаковая. Все спектры были сняты при одинаковых

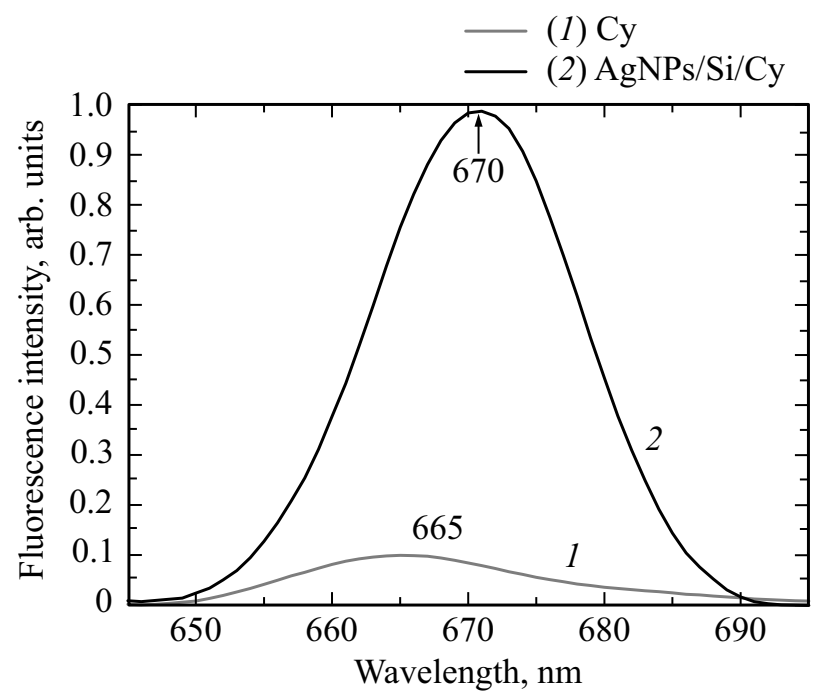

Pис. 3. Нормированные спектры флуоресценции тонкой пленки цианинового красителя (1) и тонкой пленки цианинового красителя на поверхности серебра с кремнием (2). Длина волны возбуждения $590 \mathrm{~nm}$.

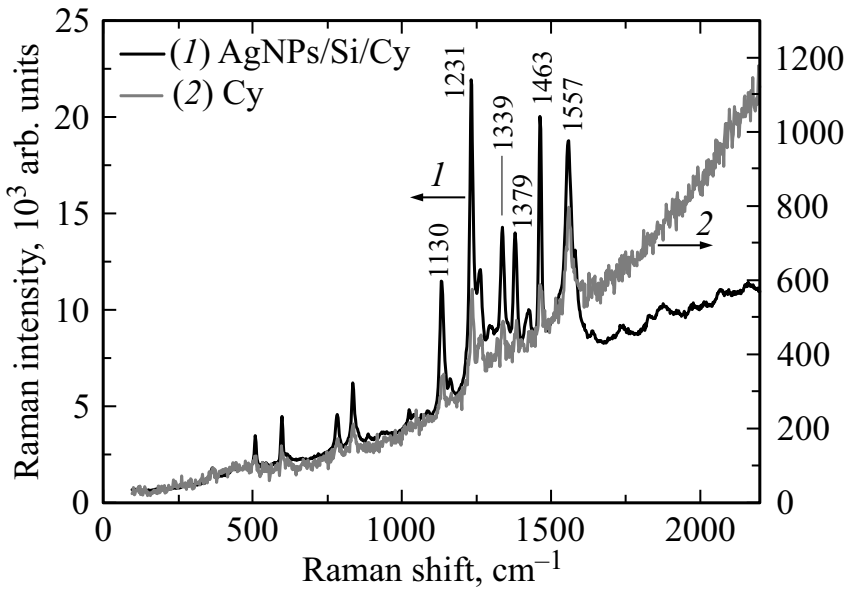

Рис. 4. Спектры комбинационного рассеяния тонкой цианиновой пленки на поверхности серебра с кремнием (1) (левая ось) и тонкой цианиновой пленки на чистой кварцевой подложке (2) (правая ось).

условиях, длина волны возбуждения составляла $590 \mathrm{~nm}$. Из рисунка видно, что в тонкой цианиновой пленке на поверхности $\mathrm{AgNPs} / \mathrm{Si}$ наблюдается значительное (в 10 раз) усиление флуоресценции, а также небольшой сдвиг в длинноволновую область $(5 \mathrm{~nm})$ по сравнению с цианиновой пленкой на поверхности прозрачной подложки. Усиление и сдвиг флуоресценции молекул красителя связано с влиянием ближнего поля плазмонных наночастиц.

На рис. 4 представлены спектры комбинационного рассеяния исследуемых образцов. Интенсивности сигналов комбинационного рассеяния образцов сильно отличаются, поэтому вертикальная ось слева с максимумом 25000 относительных единиц соответствует интенсивности комбинационного рассеяния на цианиновой пленке на поверхности $\mathrm{AgNPs} / \mathrm{Si}(1)$, а вертикальная ось справа с максимумом 1200 относительных единиц соответствует тонкой цианиновой пленке на чистой кварцевой подложке (2). Толщина цианиновой пленки в обоих образцах была одинакова. Длина волны возбуждения составляла $488 \mathrm{~nm}$.

Как видно из рис. 4, интенсивность комбинационного рассеяния молекул красителя на поверхности композитной структуры $\mathrm{AgNPs} / \mathrm{Si}$ (кривая 1) значительно больше, чем на поверхности чистой кварцевой подложки. Хотя сдвигов пиков не наблюдается, различные комбинационные линии усилены в разной степени. Например, интенсивность пика, соответствующего комбинационной частоте $1231 \mathrm{~cm}^{-1}$, увеличена в 38 раз. Наиболее важным является тот факт, что комбинационные линии, трудно различимые в спектре, полученном на чистой кварцевой подложке (кривая 2), в спектре, полученном на композитной структуре (кривая 1), могут быть легко обнаружены, несмотря на то, что интенсивность фона тоже значительно возросла. 


\section{Заключение}

Таким образом, в работе показано, что на поверхности созданной композитной структуры $\mathrm{Ag} N P S / \mathrm{Si}$ наблюдается 10-кратное усиление интенсивности флуоресценции и почти 40-кратное усиление интенсивности комбинационного рассеяния молекул цианинового красителя. Полученные величины усиления как флуоресценции, так и комбинационного рассеяния далеки до рекордных [17]. Несмотря на это, полученный композитный материал обладает рядом достоинств. Прежде всего кремниевая пленка обладает гораздо большей механической прочностью, чем серебряная, и надежно защищает ее от повреждений. Кроме того, серебряная островковая пленка при контакте с растворами красителей меняет свою морфологию и оптические свойства, в то время как в проведенных экспериментах пленка $\mathrm{AgNPs} / \mathrm{Si}$ выдерживала многократно процессы нанесения органических веществ, и при этом ее оптическая плотность не изменялась.

Таким образом, в работе создана композитная структура на основе островковой пленки серебра с тонким защитным слоем кремния, которая может быть применена в качестве ГКР-активной поверхности с умеренным, но хорошо воспроизводимым усилением и возможностью многократного использования.

Работа выполнена при поддержке РФФИ (грант № 1632-00165), гранта президента РФ (№ МК-228.2017.2) и Министерства образования и науки РФ в рамках госзадания (3.4903.2017/6.7).

\section{Список литературы}

[1] Ritchie G., Burstein E. // Phys. Rev. B. 1981. V. 24. N 8. P. 4843. doi: 10.1103/PhysRevB.24.4843

[2] Kelly K.L., Coronado E., Zhao L., Schatz G.C. // J. Phys. Chem. 2003. V. 107. N 3. P. 668. doi: 10.1021/jp026731y

[3] Климов В.В. Наноплазмоника / 2-е изд., испр. М.: Физматлит, 2010. $480 \mathrm{c}$.

[4] Toropov N.A., Kaliteevskaya E.N., Leonov N.B., Vartanyan T.A. // Opt. Spectrosc. 2012. V. 113. N 6. P. 616; Торопов Н.А., Калитеевская Е.Н., Леонов Н.Б., Вартанян T.A. // Опт. и спектр. 2012. Т. 113. № 6. С. 684.

[5] Toropov N.A., Kamalieva A.N., Vartanyan T.A. // Int. J. Nanotechnology. 2016. V. 13. N 8/9. P. 642. doi: 10.1504/IJNT.2016.079667

[6] Van Duyne R.P., Jeanmaire D.L., Shriver D.F. // Analytical Chem. 1974. V. 46. N 2. P. 213. doi: 10.1021/ac60338a012

[7] Jeanmaire D.L., Van Duyne R.P. // J. Electroanalytical Chem. and Interfacial Electrochem. 1977. V. 84. N 10. P. 1. doi: 10.1016/S0022-0728(77)80224-6

[8] Fleischmann M., Hendra P.J., McQuillan A.J. // Chem. Phys. Lett. 1974. V. 26. N 2. P. 163. doi: 10.1016/0009-2614(74)85388-1

[9] Набиев И.Р., Ефремов Р.Г., Чуманов Г.Д. // УФН. 1988. T. 154. № 3. C. 459. doi: 10.3367/UFNr.0154.198803d.0459
[10] Yonzon C.R., Stuart D.A., Zhang X.Y., McFarland A.D., Haynes C.L., Van Duyne R.P. // Talanta. 2005. V. 67. N 3. P. 438. doi: 10.1016/j.talanta.2005.06.039

[11] Sharma B., Frontiera R.R., Henry A.-I., Ringe E., Van Duyne R.P. // Materials Today. 2012. V. 15. P. 16. doi: 10.1016/S1369-7021(12)70017-2

[12] Gudun K., Elemessova Z., Khamkhash L., Ralchenko E., Bukasov R. // J. Nanomater. 2017. V. 2017. P. 9182025. doi: $10.1155 / 2017 / 9182025$

[13] Povolotskiy A., Povolotckaia A., Petrov Y., Manshina A., Tunik S. // Appl. Phys. Lett. 2013. V. 103. P. 113102. doi: $10.1063 / 1.4820841$

[14] Borodinova T.I., Kravets V.G., Romanyuk V.R. // J. Nanoand Electronic Phys. 2012. V. 4. P. 2039.; Бородинова Т.И., Кравеи, В.Г., Романюк В.Р. // Журн. нано- электрон. физ. 2012. T. 4. № 2. C. 02039.

[15] Vartanyan T.A., Leonov N.B., Przhibel'skǐ S.G., Khromov V.V. // Opt. Spectrosc. 2009. V. 106. N 5. P. 697; Bapmaнян Т.А., Леонов Н.Б., Пржибельский С.Г., Хромов В.В. // Опт. и спектр. 2009. Т. 106. № 5. С. 776.

[16] Leonov N.B., Przhibel'skii S.G., Vartanyan T.A. // Opt. Quant. Electron. 2017. V. 49. P. 127. doi: 10.1007/s11082-017-0969-8

[17] Tam F., Goodrich G.P., Johnson B.R., Halas N.J. // Nano Lett. 2007. V. 7. P. 496. doi: $10.1021 / \mathrm{n} 1062901 \mathrm{x}$ 